\title{
Resenha: Accessing Academic Discourse
}

\author{
Orlando Vian Junior \\ Universidade Federal de São Paulo - UNIFESP - São Paulo - Brasil
}

A coletânea Accessing academic discourse, organizada por James R. Martin, Karl Maton e Yaegan Doran, professores pesquisadores da Universidade de Sydney, tem como ponto de partida o pressuposto de que ter acesso ao discurso acadêmico e poder compreendê-lo e usá-lo de forma apropriada aos propósitos sociocomunicativos que se quer atingir é um modo de se atingir sucesso acadêmico, bem como poder embasar a justiça social e acessar e compartilhar o conhecimento.

Com base nesse pressuposto, a coletânea tem seu objetivo alicerçado em duas perspectivas teóricas, refletidas tanto no subtítulo da obra (Systemic Functional Linguistics and Legitimation Code Theory) quanto na sua dedicatória: In memory of Michael and Basil, ou seja, Michael Halliday, idealizador da Linguística Sistêmico-Funcional (LSF) e Basil Bernstein, idealizador da teoria dos códigos desenvolvida posteriormente por Karl Maton no que hoje conhecemos como Teoria dos Códigos de Legitimação (TCL).

Como forma de estabelecer essa interface teórico-metodológica entre a LSF e a TCL, a obra está organizada em dez capítulos, divididos em quatro seções, cuja dinâmica legitima as relações entre as teorias. No capítulo 1 (Academic discourse: an interdisciplinary dialogue), Martin estabelece o diálogo interdisciplinar, em que as teorias se complementam com o fito de lançar luzes sobre o discurso acadêmico, abordando, como indicado pelo autor, "o diálogo com a TCL pelo ponto de vista da LSF" (p. 24).

Apresentada em obra anterior de Maton (2014), a TCL inclui propostas de linguagens analíticas que permitem teorizar as dimensões sociais e epistêmicas do conhecimento humano. Também de suma importância para a compreensão da TCL são as teorias dos códigos de Bernstein e a de campo de Bordieu. Além disso, o conjunto de instrumentos analíticos para a TCL inclui conceitos para análise dos tipos dos códigos para que se compreendam como se estruturam as relações entre os conhecimentos disciplinares e os conhecedores que os produzem em determinada área.

Para apresentar aos leitores como esses conhecimentos são veiculados e tomando-se por bases as premissas interdisciplinares estabelecidas por Martin no capítulo 1, a primeira parte da obra (Legitimation Code Theory: opening ideas), composta por dois textos, aborda conceitos da TCL, principalmente os códigos de especialização e como estes se estabelecem as partir das noções de conhecimento e conhecedor e como se relacionam no sucesso de estudantes, seguido por um capítulo sobre gravidade semântica e densidade semântica em textos acadêmicos. A ideia de ondas semânticas, apresentada previamente em Maton (2013), está relacionada aos mecanismos linguísticos utilizados para reforçar ou diminuir a gravidade e a densidade semântica. A esse movimento ele nomeia de ondas semânticas.

A segunda parte (Systemic functional linguistics: responses to $L C T$ ) compõe-se de dois textos em que conceitos da Linguística SistêmicoFuncional relacionados ao registro e suas variáveis de campo e modo dialogam nos discursos acadêmicos da História, Ciências e Humanidades e como estes contribuem para a construção do discurso dessas 
áreas, em diálogo entre o contexto e a gravidade semântica dos textos, na interface LCT/LSF.

Na parte 3 (Bringing SFL and LCT together to explore knowers and values), são estabelecidas, por meio dos dois capítulos que a compõem, questões de axiologia e atitudes no discurso jornalístico e os processos da LSF, no texto de Doran, no capítulo 6, e em textos de História na interação em sala de aula, no capítulo de Oteíza, em que a autora apresenta como ocorre o discurso da ditadura chilena em aulas de História e como os eventos históricos compõem o discurso disciplinar da área de História.

Na quarta e última parte, intitulada Academic discourse in the classroom, três textos debatem a questão do discurso na sala de aula, sendo que o capítulo 8, de Susan Hood, discute a questão da presença e da linguagem corporal e sua contribuição para a construção do conhecimento. Os capítulos 9 e 10, de autoria de David Rose, abordam a questão da metalinguagem pedagógica para implementação dos gêneros do currículo e dos gêneros do conhecimento da pedagogia com base em gêneros proposta pela Escola de Sydney, como proposta em Rose e Martin (2012). O capítulo 9 está relacionado especificamente aos gêneros do currículo, ao passo que o capítulo 10 aborda os gêneros do conhecimento. Os capítulos são bastante relevantes para pesquisadores que utilizam o ciclo de ensino e aprendizagem proposto pela pedagogia com base em gêneros da Escola de Sydney, com uma circulação bastante acentuada pelas cinco regiões brasileiras por pesquisadores e profissionais envolvidos com o ensino de leitura e escrita.

Para o público de pesquisadores brasileiros em LSF, a obra é mais do que bem-vinda, principalmente por estabelecer o diálogo com a TCL, ainda com pouca circulação no Brasil e restrita a alguns centros de pesquisa. A coletânea ora resenhada, no entanto, operacionaliza muitos dos conceitos apresentados por Maton (2014) na obra em que propõe a TCL e os contextualiza em análises e aplicações do discurso acadêmico. Trata-se de leitura instigante que possibilita que se vislumbrem novos horizontes de pesquisa para aqueles interessados no discurso acadêmico e de uma nova interface da LSF, uma teoria de longa tradição e com muitas pesquisas objetivando a compreensão da linguagem, com a TCL, uma abordagem mais recente, mas que vem crescendo rapidamente e que permite explorar práticas de construção de conhecimento.

\section{REFERÊNCIAS}

MATON, Karl. Knowledge and knowers: towards a realist sociology of education. London and New York: Routledge, 2014

MATON, Karl. Making semantic waves: a key to cumulative knowledge-building. Linguistics and Education, 24(1), 8-22. 2013.

ROSE, David; MARTIN, James R. Learning to Write, Reading to Learn: Genre, Knowledge and Pedagogy in the Sydney School. London: Equinox, 2012.

\section{COMO CITAR ESSE ARTIGO}

VIAN JR, Orlando. Resenha: Accessing Academic Discourse. Signo, Santa Cruz do Sul, v. 46, n. 86, p. 197198, jun. 2021. ISSN 1982-2014. Disponível em: <https://online.unisc.br/seer/index.php/signo/article/view/ 16662>.doi:https://doi.org/10.17058/signo.v46i86.16662. 